\title{
VIII Evaluation
}

Zu der empfohlenen Vorgehensweise bei der Entwicklung von Leitlinien gehört deren Evaluation [AWMF/ÄZQ 2001]. Hierzu ist eine externe Evaluation der Leitlinie in Form einer prospektiven und kontrollierten Untersuchung erstrebenswert. Zielgröße ist hierbei die Datenqualität, bestimmt einerseits über die einzelnen Qualitätsindikatoren sowie andererseits über den Qualitätsscore. Einzelne Berichte zur Anwendung der Leitlinie in Version 1.o wurden veröffentlicht [Jacke et al. 2012a, Jacke et al. 2012b, Prokein et al. 2011]. Eine systematische Evaluation der Leitlinie steht noch aus. 